\title{
The immigration of anaemia - presentation of sickle cell disease in children admitted to a district hospital in Johannesburg: A case series
}

\author{
D M Azar, MB BCh \\ Department of Paediatrics, Charlotte Maxeke Johannesburg Academic Hospital, Faculty of Health Sciences, University of the Witwatersrand, \\ Johannesburg, South Africa
}

Corresponding author: D M Azar (danielazar1234@gmail.com)

\begin{abstract}
Sickle cell disease (SCD) is the most common monogenic disorder and haemoglobinopathy worldwide and is unique in its distribution to tropical, malaria-endemic regions. SCD is typically rare in South Africa (SA) but the increasing immigration of foreign nationals over the last 20 years has the potential to alter the epidemiology of this life-threatening disease. With recent data from the Western Cape showing an increase in disease frequency, more evidence needs to be collected to determine the changes in the disease profile locally. This case series reviews the presentation and outcome of three patients diagnosed with SCD at a district hospital in Johannesburg, Gauteng.
\end{abstract}

S Afr J Child Health 2018;12(2):79-80. DOI:10.7196/SAJCH.2018.v12i2.1463

Sickle cell disease (SCD) is the most common monogenic disorder and affects $\sim 70$ million individuals worldwide, with the burden of disease uniquely distributed to malaria-endemic regions. ${ }^{[1]}$ SCD is typically rare in South Africa (SA) but the increasing immigration of foreign nationals over the last 20 years has the potential to alter the epidemiology of this life-threatening disease locally. The abolishment of the apartheid regime and its laws has made immigration to SA more appealing to foreigners. This, along with political strife, poverty, war and famine in many other African countries, has resulted in an influx of foreign nationals into the country. ${ }^{[2]}$

The exact number of immigrants living in SA is not known; however, according to the United Nations High Commissioner for Refugees, 463 040 asylum seekers and 112192 refugees reside in SA. ${ }^{[3]}$ Recent data from Stats SA show that a significant influx of foreign nationals is seen each year and 106173 temporary residence permits were issued in 2013 alone. ${ }^{[4]}$ The majority of immigrants were from African countries (54.4\%), with Zimbabwe, Nigeria, the Democratic Republic of Congo (DRC), Lesotho, Malawi, Angola and Cameroon the most common nations. ${ }^{[4]}$

It is therefore not surprising that patients with SCD are seen more frequently in our hospitals and clinics. At the Red Cross War Memorial Children's Hospital in the Western Cape, the annual frequency of SCD increased by $300-400 \%$ between 2001 and $2010 .{ }^{[5]}$ All patients who have undergone genetic screening for sickle cell anaemia with the Department of Human Genetics at the National Health Laboratory Services (NHLS) in Johannesburg between 1983 and 2012 were foreign nationals and the majority were imigrants from sub-Saharan African countries, including the DRC, Angola, Nigeria and Zimbabwe ${ }^{[6]}$ More evidence needs to be collected to determine the changes of the disease profile locally. A retrospective descriptive study was carried out to review all paediatric admissions over a 16-month period at South Rand Hospital (SRH), a district hospital in Johannesburg, Gauteng Province. Patients who were admitted with SCD were identified and their clinical records were analysed to determine their presentation and outcome.

\section{Case 1}

A four-year-old boy, who was born in the DRC and living in SA as an asylum seeker, presented to SRH for admission on two occasions for complications arising from SCD. He first presented with a two- day history of vomiting, fever, non-productive cough and diarrhoea. The patient was noted to be lethargic and pale on examination, with mild dehydration and inflammation of the pharynx and tonsils. A diagnosis of pharyngitis was made. SCD was considered on the basis of his ethnicity and pale complexion. The patient was admitted and investigated for a local source of infection. A blood and urine culture, full blood count (FBC) and C-reactive protein (CRP) assay were performed. He was treated empirically with intravenous broadspectrum antibiotics (amikacin and ceftriaxone), given paracetamol for analgesia, supplemented with folic acid and rehydrated with alkali fluids (1 L 5\% dextrose water supplemented with $10 \mathrm{~mL}$ $15 \%$ potassium chloride and $50 \mathrm{~mL} 8.5 \%$ sodium bicarbonate) at $70 \mathrm{~mL} / \mathrm{kg} /$ day.

The FBC with a smear revealed hypochromic anaemia $(\mathrm{Hb} 7.1 \mathrm{~g} / \mathrm{dL})$ with marked anisocytosis and moderate sickle cells. This prompted investigation with haemoglobin $(\mathrm{Hb})$ electrophoresis that showed significantly elevated levels of $\mathrm{HbF}(16.2 \%)$ and $\mathrm{HbS}$ (78.5\%), with decreased levels of $\mathrm{HbA}(2.3 \%)$ and an $\mathrm{HbA} 2$ of $3 \%$. Further studies revealed the absence of $\mathrm{HbH}$, a normal glucose6-phosphate dehydrogenase (G-6-PD) level and a reticulocyte production index (RPI) of 3.7. These findings were in keeping with homozygous SCD. An infective locus could not be identified. The patient's clinical condition improved during admission and he was well for discharge after five days of treatment. He was discharged on oral penicillin VK and folic acid, with a follow-up arranged at the haematology clinic at Charlotte Maxeke Johannesburg Academic Hospital (CMJAH).

One month later, the patient presented to SRH with a complaint of lower abdominal pain and lethargy for two days. He was noted to be pale and irritable with generalised abdominal tenderness without organomegaly. He was admitted with a diagnosis of an abdominal sickle cell crisis. A treatment approach similar to the first admission was followed and the patient was well for discharge after 5 days.

\section{Case 2}

A one-year-old boy, born in the DRC and living in SA with an unknown immigration status, presented to SRH with painful swelling of both feet. The swelling was reported to have started insidiously and had been present for two days. A diagnosis of septic arthritis was considered. A radiograph of the feet and ankles revealed 
no abnormalities but a FBC with a smear revealed a hypochromic, microcytic anaemia $(\mathrm{Hb} 8.2 \mathrm{~g} / \mathrm{dL})$ with teardrop cells, scanty pencil cells, target cells and mild poikilocytosis. This prompted investigation with $\mathrm{Hb}$ electrophoresis that showed significantly elevated levels of $\mathrm{HbF}(19.1 \%)$ and $\mathrm{HbS}(77.9 \%)$ with decreased levels of $\mathrm{HbA} 2(0 \%)$ and an $\mathrm{HbA}$ of $3 \%$. Further studies revealed the absence of $\mathrm{HbH}$, a normal G-6-PD level and an RPI of 2.8. The findings were in keeping with homozygous sickle cell disease. Managed as an outpatient, he was put onto folic acid and prophylactic oral penicillin VK and arrangements were made for follow-up at the haematology clinic at CMJAH.

Four weeks after the confirmation of SCD, the patient presented in an acute pain crisis. He was noted to have a two-day history of generalised pain accompanied by a fever and lethargy. Examination revealed pallor with marked irritability, distress on handling and generalised abdominal tenderness. The patient was admitted and investigated for a local source of infection. A blood and urine culture, FBC and CRP were performed. He was treated empirically with intravenous broad-spectrum antibiotics (ampicillin and ceftriaxone), supplemented with folic acid, given paracetamol for analgesia and rehydrated with alkali fluids at $130 \mathrm{~mL} / \mathrm{kg} / \mathrm{day}$. An infective locus could not be identified. The patient's clinical condition improved and he was well for discharge after 7 days of treatment. He was discharged on oral penicillin VK and folic acid with a follow-up arranged at the haematology clinic at CMJAH.

\section{Case 3}

An eleven-month-old boy, born in Nigeria and living in SA with an unknown immigration status, presented to SRH after being referred from the local clinic with jaundice. Further questioning revealed a one-day history of vomiting with abdominal distention and lethargy without the presence of pruritis or discoloured urine or stool. The child was obviously jaundiced with abdominal distention and generalised pain. A $2 \mathrm{~cm}$ hepatomegaly with a rounded edge and smooth surface without splenomegaly was noted two days after admission. The patient was admitted and investigated for a local source of infection. A blood and urine culture, FBC, CRP and a liver function test (LFT) were performed. He was treated empirically with intravenous broad-spectrum antibiotics (amikacin and ceftriaxone), given paracetamol for analgesia and rehydrated with half-strength Darrow's solution at $70 \mathrm{~mL} / \mathrm{kg} /$ day.

A FBC with a smear on admission revealed a hypochromic, microcytic anaemia ( $\mathrm{Hb} 7.3 \mathrm{~g} / \mathrm{dL}$ ) with target cells, spherocytes, oval macrocytes, poikilocytosis and Howel Jolly bodies. This prompted investigation with $\mathrm{Hb}$ electrophoresis that showed significantly elevated levels of $\mathrm{HbF}(16.3 \%)$ and $\mathrm{HbS}(80.7 \%)$, with decreased levels of $\mathrm{HbA} 2(3 \%)$ and an $\mathrm{HbA}$ of $0 \%$. Further studies revealed the absence of $\mathrm{HbH}$, a normal G-6-PD level and an RPI of 2.5. The patient also had a raised CRP of $184 \mathrm{mg} / \mathrm{L}$ and deranged LFTs with an unconjugated hyperbilirubinaemia and elevated ductal enzymes, i.e. alkaline phosphatase (ALP) and gamma-glutamyl transferase (GGT). The findings were in keeping with homozygous SCD complicated by acute haemolysis. An infective locus could not be identified. The patient's clinical condition improved and he was well for discharge after 7 days of treatment. He was discharged on oral penicillin VK and folic acid with a follow-up arranged at the haematology clinic at CMJAH.

\section{Conclusion}

Although SCD is rare in SA, it is being diagnosed and managed at the district level in Johannesburg. The changing demographics of SA should raise suspicion of this increasingly prevalent, life-threatening disease. SCD is a great masquerader with a wide range of differential diagnoses. Diagnosis of the disease should be considered in patients who are inherently at risk with suspicious symptoms. This requires an understanding of the background and ethnicity of the population group being treated. Management of the disease is complex. The acute crisis requires urgent care and, to prevent such crises and minimise long-term complications, long-term follow-up should be done at a specialist institution where available.

Acknowledgements. Dr Ramatsimele Mphahlele provided valuable advice and direction on the topic.

Author contributions. Sole author.

Funding. Self-funded.

Conflicts of interest. None.

1. Nazeer A, Moosa P, Hassan A, et al. Recommendations for the management of sickle cell disease in South Africa. S Afr Med J 2014;104(11):743-751. https:// doi.org/10.7196/samj.8470

2. Statistics South Africa (STATS SA). Community Survey 2016 - statistical release. Johannesburg: STATS SA, 2016. http://cs2016.statssa.gov.za/wpcontent/uploads/2016/07/NT-30-06-2016-RELEASE-for-CS-2016-_Statisticalreleas_1-July-2016.pdf (accessed 1 March 2017).

3. United Nations High Commisioner for Refugees (UNHCR). UNHCR operation in South Africa, Lesotho and Swaziland - September 2015 factsheet. Pretoria: UNHCR, 2015. http://www.unhrc.org (accessed 4 July 2017).

4. Statistics South Africa (STATS SA). Documented Immigrants in South Africa 2013. Johannesburg: STATS SA, 2013. http://beta2.statssa.gov.za/publications/ D03514/D035142013.pdf (accessed 1 March 2017).

5. Ambroise W, Chido P, Nan N, et al. The burden of sickle cell disease in Cape Town. S Afr Med J 2012;102(9):752-754. https://doi.org/10.7196/samj.5886

6. Krause A, Wainstein T, Essop FB, Goodyear Q. Testing for haemoglobinopathies in Johannesburg, South Africa: A 30-year review. SAMJ 2013;103(12):989-993. https://doi.org/10.7196/samj.7255

Accepted 10 April 2018. 